Beobachtungen von Perseus-Sternen.

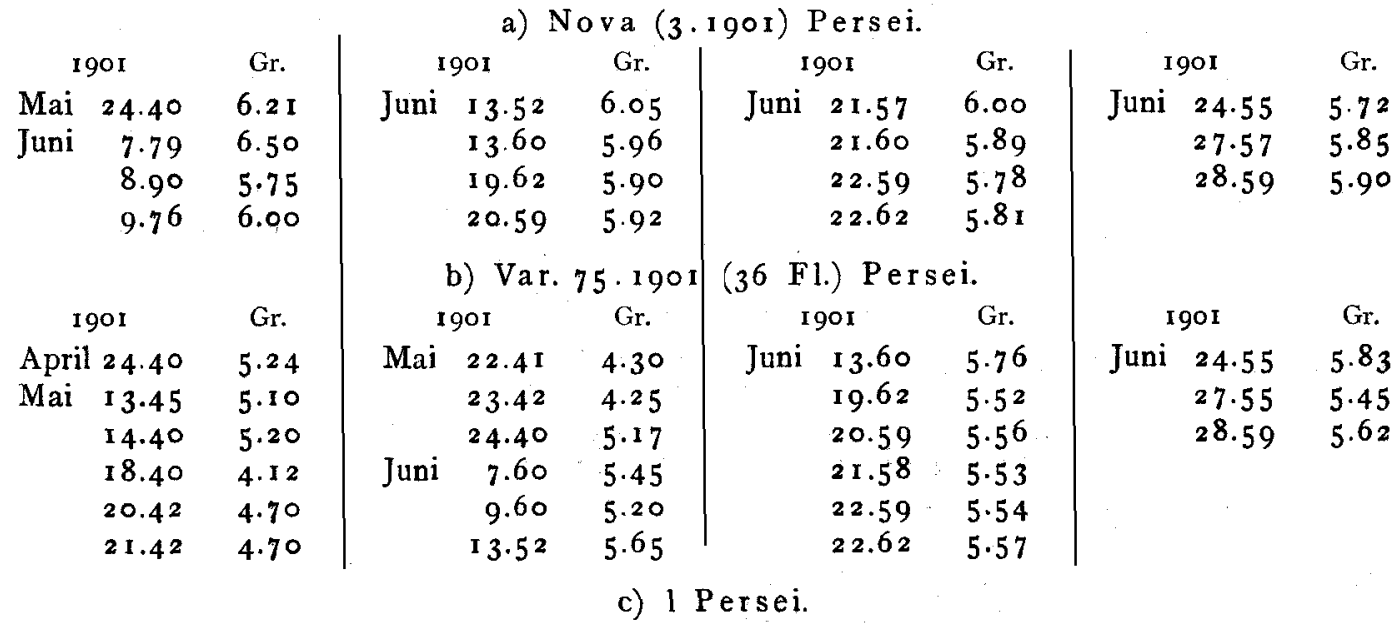

Die Bearbeitung des Materials bezüglich der Nova Persei liess es mir schon seit Wochen schwierig erscheinen, Mittelwerthe zu bilden, sobald die Sterne $36 \mathrm{Fl}$. und I benutzt worden waren. Nachdem nun für 36 Fl. die Sachlage geklärt ist, habe ich auch den nächst verdächtigten, l Persei, einzeln berechnet und folgende Grössen abgeleitet:

\begin{tabular}{|c|c|c|c|c|c|c|c|c|c|c|c|}
\hline \multicolumn{2}{|c|}{1901} & Gr. & \multicolumn{2}{|c|}{1901} & Gr. & \multicolumn{2}{|c|}{ I9OI } & Gr. & \multicolumn{2}{|c|}{ I 901} & Gr. \\
\hline März & 24.35 & 4.65 & $\mathrm{Mai}$ & $18.4^{\circ}$ & 5.15 & Juni & 10.59 & 6.10 & Juni & 24.55 & $5.4 \mathrm{I}$ \\
\hline & 26.33 & 4.80 & & 20.42 & 4.60 & & 13.52 & 5.45 & & 27.55 & 5.42 \\
\hline April & 20.40 & 5.60 & & 21.42 & $5 \cdot 15$ & & 19.62 & 5.40 & & 28.59 & 5.45 \\
\hline Mai & 7.40 & 5.60 & & $22.4 \mathrm{I}$ & 5.15 & & 20.59 & 5.40 & & & \\
\hline & $8.4^{2}$ & 4.70 & Juni & 7.60 & 5.80 & & $21 \cdot 5^{8}$ & 5.44 & & & \\
\hline & 14.41 & $5 \cdot 54$ & & $8.6 \mathrm{I}$ & 5.15 & & $22.6 \mathrm{I}$ & $5 \cdot 52$ & & & \\
\hline
\end{tabular}

Landstuhl, Pfalz, I 90 I Juni.

Ph. Fauth.

Zusatz des Herausgebers. Die angegebenen Beobachtungen von 1 Persei scheinen mir zur Constatirung einer thatsächlichen Veränderlichkeit des Sterns noch nicht ausreichend zu sein, so dass ich zunächst von einer Numerirung absehen möchte. Eine mir von Dr. Guthnick in Bonn gütigst mitgetheilte längere Beobachtungsreihe von 1 Persei von März 28 bis Mai 23 zeigt übrigens innerhalb der Beobachtungsdauer eine völlige Constanz des Lichts, im Mittel, vorbehaltlich genauerer Reduction, $5 \div \mathbf{m} 2$.

$K r$.

\title{
Verbesserte Ephemeride des Encke'schen Cometen 1901 b.
}

Auf Grundlage der Beobachtung von Sokolow in Pulkowo von Aug. 11.5 wurde eine Correction von -4' $4^{\prime \prime}$ an die mittlere Anomalie angebracht und eine neue Ephemeride des Cometen gerechnet.

oh M. Z. Berlin.

\begin{tabular}{|c|c|c|c|c|c|c|c|c|c|c|c|c|}
\hline \multicolumn{2}{|c|}{ I 901} & $\alpha$ app. & $\delta$ app. & $\log r$ & $\log A$ & Ab. $-Z$. & 1901 & $\alpha$ app. & $\delta$ app. & $\log r$ & $\log A$ & Ab.-Z. \\
\hline Aug. & $\begin{array}{l}25 \\
26\end{array}$ & $\begin{array}{cc}8^{\mathrm{h}} 24^{\mathrm{m}} & 4^{\mathrm{s}} \\
3^{2} & 9\end{array}$ & $\begin{array}{r}+25^{\circ} 57: 8 \\
2518.6\end{array}$ & $\begin{array}{r}9.8012 \\
7884\end{array}$ & $\begin{array}{r}0.0989 \\
0982\end{array}$ & $\begin{array}{r}10^{\mathrm{m}} 26^{\mathrm{s}} \\
25\end{array}$ & Aug. $\begin{array}{r}3^{\circ} \\
3^{I}\end{array}$ & $\begin{array}{r}9^{\mathrm{h}} 4^{\mathrm{m}} 33^{\mathrm{s}} \\
124 \mathrm{I}\end{array}$ & $\begin{array}{rr}+22^{\circ} & 18: 4 \\
21 & 27.6\end{array}$ & $\begin{array}{r}9.733^{8} \\
719^{2}\end{array}$ & $\begin{array}{r}0.0981 \\
0987\end{array}$ & $\begin{array}{r}10^{\mathrm{m}} 25^{\mathrm{s}} \\
26\end{array}$ \\
\hline & 27 & $40 \quad 14$ & 2437.0 & 7753 & 0978 & 25 & Sept. I & $20 \quad 48$ & 2034.5 & 7042 & 0996 & 27 \\
\hline & 28 & $48 \quad 20$ & 2353.1 & 7618 & $097^{6}$ & 24 & 2 & $28 \quad 55$ & 1939.3 & 6891 & 1006 & 29. \\
\hline & 29 & $\begin{array}{lll}8 & 56 & 26\end{array}$ & 236.9 & 7480 & 0977 & 24 & 3 & 372 & $18 \quad 41.9$ & 6737 & 1019 & $3 \mathbf{I}$ \\
\hline & 30 & 9433 & $+22 \times 8.4$ & $9.733^{8}$ & $0.098 \mathrm{I}$ & 10 25 & 4 & 945 & +1742.3 & 9.6582 & $0.1 \circ 34$ & 1033 \\
\hline
\end{tabular}

Kronstadt, Marine-Observatorium, 1901 Aug. 12.

Ch. Thonberg.

\section{Beobachtungen des Encke'schen Cometen 1901 b.}

Am 14. August bot nach längerer Pause endlich ein um $14^{\mathrm{h}} 44^{\mathrm{m}} \mathrm{M}$. Z. Bamberg am Heliometer nach dem Coheller Morgen Gelegenheit, nach dem Encke'schen Cometen zu sehen und eine Ortsbestimmung zu versuchen. Als ich meten sah, bemerkte ich den Stern BD. +30:1430 vom. Cometen bedeckt, dessen Coma besser auf der Südseite als 